ORIGINAL ARTICLE

\title{
Reduction in Needle Stick Injury Rate among the Healthcare Workers in a Tertiary Care Hospital
}

Neha Dang ${ }^{1}$, Suryasnata Das ${ }^{2}$

\begin{abstract}
Introduction: Needle stick injuries (NSIs) are a commonly encountered underreported occupational hazard faced by healthcare workers (HCWs). Aim: The aim of the study was to determine the causes of the NSI and reduce the NSI rate among all HCWs (doctors, nurses, technicians, general duty assistants/housekeeping staff) at a tertiary care hospital.

Objectives:

- To determine the rate of NSI among various categories of HCWs at a tertiary care hospital.

- To study the causal factors and circumstances for NSIs.

- To implement corrective actions and prevent these through improvement in training, usage of safety devices, and providing a safe environment.

- To reduce the NSI rate per healthcare worker per year.

- To reduce the NSI rate below the set benchmark of the hospital, i.e., one NSI per 1,000 in-patient days.

Materials and methods: The causes for NSI were identified by collating the data from January 2016 to May 2017 and the Pareto analysis was used to find out the main factors leading to NSI. Continuous and scheduled training for nurses, doctors, phlebotomists, housekeeping staff, and general duty assistants (GDAs) on waste segregation [biomedical waste (BMW) management], handling of sharps/sharps container, and PPE usage was provided and the same was monitored by the infection control nurse and quality team during rounds. The NSI rates were presented to the clinical department heads and awareness was created among doctors to segregate the waste. Needles with safety device were made available for the nursing team for sample collection. The corrective action was implemented in the month of June 2017 and data for 3 months, i.e., June, July, and August 2017, were continuously monitored.
\end{abstract}

Results: In the study, the main reasons for NSI were improper segregation of sharps in trained HCWs (38.46\%), unavoidable accidents (30.77\%), and improper handling of sharps (11.54\%), followed by untrained person (6.41\%), recapping of the needle (5.13\%), and the safety device not being used at the time of sample collection (3.85\%). After training and awareness of HCWs and promoting use of safety devices, data were collected and analyzed. Needle stick injury per HCW per year was reduced to 0.03 (June 2017-October 2017) from 0.05 (Jan 2016-May2017). Similarly, there was reduction in the NSI rate per thousand patient days to 0.63 (June 2017-Oct 2017) from 1.19 (Jan 2016-May2017).

Conclusion: Needle stick injuries can be reduced by identifying the causative factors and implementing corrective measures like use of a safety device for sample collection, creating awareness about segregation of waste, and handling of sharps among all the HCWs including doctors.

Keywords: Biomedical waste, Healthcare workers, Needle stick injury, Occupational hazards.

International Journal of Research Foundation of Hospital and Healthcare Administration (2019): 10.5005/jp-journals-10035-1110

\section{INTRODUCTION}

Healthcare workers (HCWs) are exposed to several types of occupational hazards including sharp injuries, harmful exposure to chemicals and hazardous drugs, latex allergy, back injuries, violence, and stress. ${ }^{1}$

Needle stick injury (NSI) is one of the most common hazards in a healthcare setting. A NSI, percutaneous injury, or sharps injury is the penetration of the skin by a needle or other sharp object, which has been in contact with blood, tissue, or other body fluids before the exposure. ${ }^{2}$

Sharp injuries pose a serious threat to HCWs. Exposure to sharps carries a significant occupational risk of transmission of blood-borne pathogens, such as human immunodeficiency virus, hepatitis $B$ virus, and hepatitis $\mathrm{C}$ virus, to the HCWs. ${ }^{3}$

Healthcare workers are exposed when blood and body fluids come in contact with the mucous membrane, open wounds, nonintact skin such as observed in eczema, or percutaneous injuries. $^{4}$

Considering the risk of exposure of HCWs to deadly and dangerous blood-borne pathogens, the Needle Stick Safety and Prevention Act came into effect in April 2001 to further reduce it. The Act in the United States mandated employers to ensure the
${ }^{1}$ Department of Administration, Baba Saheb Ambedkar Medical College and Hospital, Delhi, India

${ }^{2}$ Department of Laboratory Medicine-Microbiology, Jaypee Hospital, Sector 128, Noida, Uttar Pradesh, India

Corresponding Author: Suryasnata Das, Department of Laboratory Medicine-Microbiology, Jaypee Hospital, Sector 128, Noida, Uttar Pradesh, India, Phone: +918860764401, e-mail: Suryasnatadas23@ gmail.com

How to cite this article: Dang N, Das S. Reduction in Needle Stick Injury Rate among the Healthcare Workers in a Tertiary Care Hospital. Int J Res Foundation Hosp Healthc Adm 2019;7(2):58-62.

Source of support: Nil

Conflict of interest: None

provision of safety-engineered devices for HCWs to reduce NSI exposures in hospitals. ${ }^{5}$

According to a report of the Centers for Disease Control and Prevention (CDC), on an average 385,000 sharp injuries occur annually among the HCWs in hospitals worldwide. ${ }^{6}$

Because of the environment in which HCWs work, many of them are at an increased risk of accidental NSI. It is believed that the rate is actually much higher than reported as HCWs do not consider it 
serious enough to bother and lack of the proper reporting method across the globe. More than half of the NSIs are not reported by HCWs; thus, the actual incidence is much higher and should not be underestimated. ${ }^{7}$

In India, the data on the occupational injuries are not known; thus, it is not possible to estimate an annual incidence of NSIs. ${ }^{8}$

Most common reasons observed for the underreporting of sharp injuries may be fear of contracting disease, follow-ups, huge documentation, retrenchment from job, and failure to acknowledge the potential consequences of such injuries. ${ }^{9}$

Supportive measures available to prevent infections due to sharps injuries include training of HCWs on usage of the personal protective equipment and safe working practices such as usage of safety-engineered devices, puncture-proof disposal containers, and safe injection practices. ${ }^{10}$

There is economic burden in the form of direct and indirect cost of these injuries. The cost of the postexposure management is usually borne by the healthcare administration, which includes cost of laboratory investigations of the exposed person and testing the source patient, counseling, and cost of prophylactic treatment. ${ }^{11}$

Many effective interventions have been proposed from time to time, which include adoption of safe work practices like provision of disposable containers for sharps objects, introduction of sharp devices with integrated safety feature, and education and training to reduce NSIs. ${ }^{12}$

\section{Materials and Methods}

\section{Design and Sample Population}

This is a prospective study on all HCWs including doctors, nurses, contractual staff (housekeeping and GDA), and technical staff. Needle stick injuries were identified by way of self-reporting through a needle stick reporting form structured to identify predictive factors associated with NSIs. The NSI data from January 2016 to May 2017 were reviewed for category of HCWs, training status of HCWs, cause of injury, and circumstances under which NSI occurred. The root cause analysis was done for each injury to identify the cause. The Pareto analysis was done to determine the significant causes of NSIs.

The fishbone analysis of the most significant cause was done to determine the factors responsible for it.

Post that the corrective action implementation phase was initiated for 10 days in June 2017. The NSI data were continuously monitored and the NSI rate was observed between June 2017 and October 2017.

\section{Statistical Analysis}

All data were tabulated in the Microsoft Office Excel version 2007. Only exploratory and descriptive statistics are presented and no statistical tests were applied. Illustration was done using pie charts and graphs.

\section{Results}

The analysis of data for NSIs from the month of January 2016 till May 2017 was done from the hospital infection control indicator format.

Monthwise number of NSIs, number of in-patient days, the NSI rate per 1,000 patient days, and comparison of the NSI rate between the pre- and postcorrective action phase were recorded (Table 1). Comparison of NSI per HCW per year, between the preand postcorrective action phase, was done (Table 2).

Incidence of NSI among the category of HCWs during the precorrective action phase was calculated. Among the HCWs, nurses are most prone to NSI (26\%) followed by housekeeping staff (24\%), GDA (21\%), doctors (20\%), and technicians (0\%) (Figs 1 and 2).

The root cause analysis and the Pareto analysis were done to identify the causal factors responsible for NSIs. The main reasons

Table 1: Monthwise number of needle stick injuries (NSIs), number of in-patient days, NSI rate per 1,000 patient days, and comparison of the NSI rate between the pre- and postcorrective action phases

\begin{tabular}{|c|c|c|c|c|c|c|c|}
\hline \multicolumn{4}{|c|}{ January 2016-May 2017} & \multicolumn{4}{|c|}{ June 2017-October 2017} \\
\hline Month & No. of NSIs & $\begin{array}{l}\text { No. of in-patient } \\
\text { days }\end{array}$ & $\begin{array}{l}\text { NSI per } 1,000 \\
\text { patient days }\end{array}$ & Month & No. of NSls & $\begin{array}{l}\text { No. of in-patient } \\
\text { days }\end{array}$ & $\begin{array}{l}\text { NSI per } 1,000 \\
\text { patient days }\end{array}$ \\
\hline January 2016 & 4 & 3.156 & 1.27 & June 2017 & 2 & 4.550 & 0.44 \\
\hline February 2016 & 4 & 2.924 & 1.37 & & & & \\
\hline March 2016 & 10 & 3.125 & 3.2 & & & & \\
\hline April 2016 & 3 & 3.125 & 0.96 & July 2017 & 4 & 4.920 & 0.81 \\
\hline May 2016 & 4 & 3.401 & 1.18 & & & & \\
\hline June 2016 & 4 & 2.680 & 1.49 & & & & \\
\hline July 2016 & 3 & 3.459 & 0.87 & & & & \\
\hline August 2016 & 3 & 3.716 & 0.81 & August 2017 & 4 & 5.314 & 0.75 \\
\hline September 2016 & 2 & 5.629 & 0.36 & & & & \\
\hline October 2016 & 6 & 4.411 & 1.36 & & & & \\
\hline November 2016 & 4 & 4.086 & 0.98 & September 2017 & 3 & 5.122 & 0.59 \\
\hline December 2016 & 5 & 4.052 & 1.23 & & & & \\
\hline January 2017 & 5 & 3.988 & 1.25 & & & & \\
\hline February 2017 & 2 & 3.428 & 0.58 & October 2017 & 3 & 5.608 & 0.53 \\
\hline March 2017 & 4 & 4.446 & 0.9 & & & & \\
\hline April 2017 & 7 & 4.768 & 1.47 & & & & \\
\hline May 2017 & 8 & 5.270 & 1.52 & & & & \\
\hline Total & 78 & 65.664 & & Total & 16 & 25.514 & \\
\hline $\begin{array}{l}\text { Average NSI/1,000 } \\
\text { patient days }\end{array}$ & 1.19 & & & $\begin{array}{l}\text { Average NSI/1,000 } \\
\text { patient days }\end{array}$ & 0.63 & & \\
\hline
\end{tabular}


for NSI were improper segregation by trained HCWs (38.46\%), unavoidable accidents (30.77\%), and improper handling of sharps (11.54\%), followed by untrained HCWs (6.41\%), recapping (5.13\%), needle with safety device not used for collection (3.85\%), improper segregation by untrained HCWs, improper handling of sharp container, and lack of patient counseling (1.28\% each) (Tables 3 and 4).

The fishbone analysis (Fig. 3) of the most significant cause was carried out to determine the factors that could be responsible for NSI (for the precorrective action phase).

After the reasons for NSI were determined, following steps were taken to reduce the NSI rate such as continuous and scheduled training of nurses, doctors, phlebotomist, housekeeping staff, and GDAs on waste segregation, handling of sharps, handling of sharp container, usage of the personal protective equipment, and reinforcement on using the single-use insulin (lantus) needle. Usage of the safety device in all areas and availability of a sharp container at the logistically appropriate sites (i.e., near the patient bedside/

Table 2: Comparison of needle stick injuries (NSIs) per HCW per yearbetween the pre- and postcorrective action phase

\begin{tabular}{lll}
\hline Category of staff & $\begin{array}{l}\text { Average (January } \\
\text { 2016-May 2017) }\end{array}$ & $\begin{array}{l}\text { Average (June } \\
\text { 2017-October 2017) }\end{array}$ \\
\hline Doctors & 221 & 242 \\
Nurses & 445 & 526 \\
Contractual staff & 336 & 326 \\
(housekeeping and GDA) & & \\
Technical staff & 204 & 227 \\
Total HCWs & 1.206 & 1.321 \\
NSI rate per HCW & 0.06 & 0.01 \\
NSI rate per HCW per year & 0.05 & 0.03 \\
\hline
\end{tabular}

waste generation site) were ensured. Size of the sharp container was changed as per usage in the area to avoid overfilling and repeated change of the container in a day. Brochures on infection control were prepared and used for educating the patients/attendants. Adequate display of BMW posters was done in all areas. Further monitoring of segregation of waste by the infection control nurse and quality team during rounds and audits was done.

Since the improvement phase was started in the month of June, thereafter all the actions were taken to reduce the NSI rate. It is evident from Tables 1 and 2 that there was reduction in both the NSI rate per 1,000 patient days and the NSI rate per HCW per year post implementation of measures from 1.19 to 0.63 and 0.05 to 0.03 , respectively.

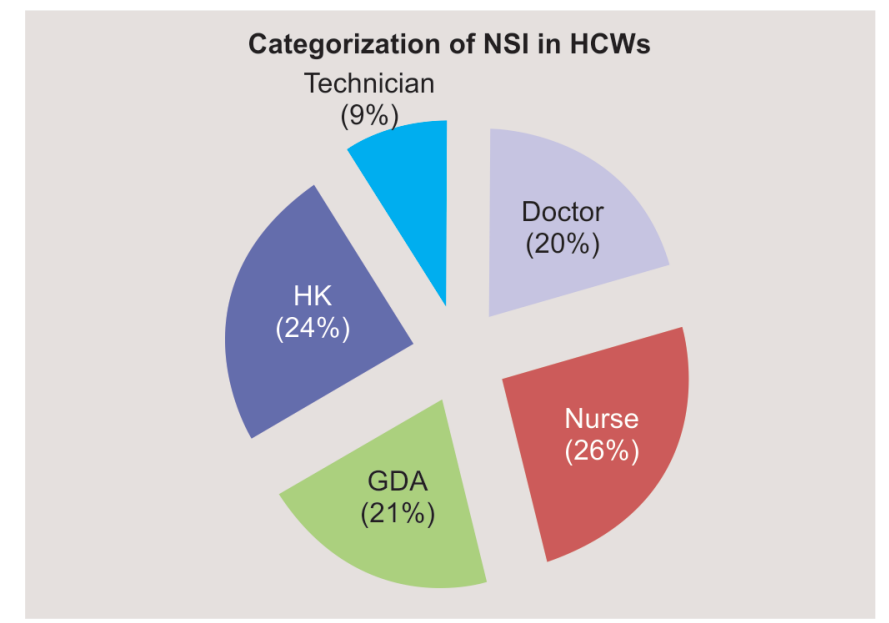

Fig. 1: Needle stick injury incidence among the healthcare workers during the precorrective action phase

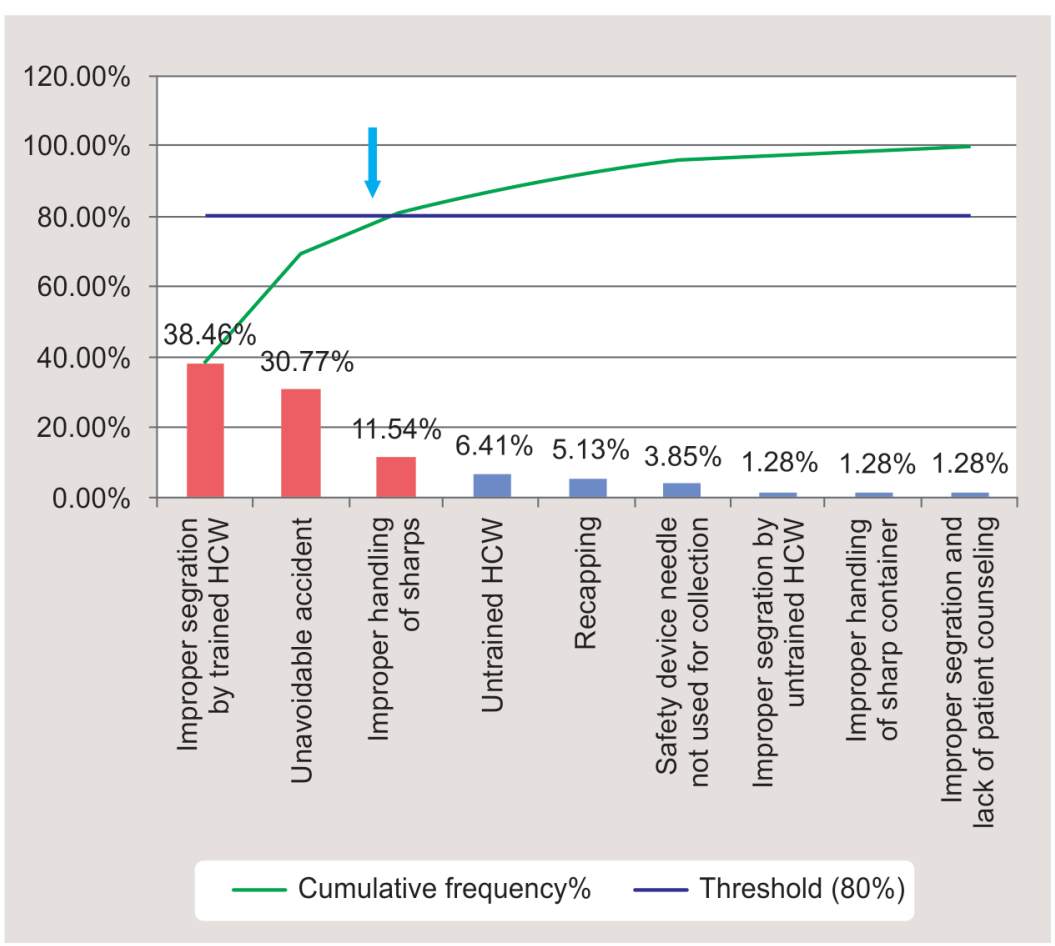

Fig. 2: Pareto analysis for needle stick injury causal factors (for the precorrective action phase). The cumulative percentage is shown with the green line in the graph and the purple line in the graph represents cutoff at $80 \%$. The intersection of green and purple lines shows us which parameters are vital few (red bars), i.e., $20 \%$ of the causes accounting for $80 \%$ of the problems and trivial many (blue bars) 
Table 3: Pareto analysis depicting frequency, cumulative frequency, percentage, and cumulative percentage for different types of causes for the precorrective action phase

\begin{tabular}{|c|c|c|c|c|}
\hline Causal factor & Frequency & $\begin{array}{l}\text { Cumulative } \\
\text { frequency }\end{array}$ & $\begin{array}{l}\text { Causal } \\
\text { factors (\%) }\end{array}$ & $\begin{array}{l}\text { Cumulative } \\
\text { frequency (\%) }\end{array}$ \\
\hline Improper segregation by trained $\mathrm{HCWs}$ & 30 & 30 & 38.46 & 38.46 \\
\hline Unavoidable accident (while suturing) & 24 & 54 & 30.77 & 69.23 \\
\hline Improper handling of sharps & 9 & 63 & 11.54 & 80.77 \\
\hline Untrained HCWs & 5 & 68 & 6.41 & 87.18 \\
\hline Recapping by HCWs & 4 & 72 & 5.13 & 92.31 \\
\hline Needle with safety device not used for collection & 3 & 75 & 3.85 & 96.15 \\
\hline Improper segregation by untrained HCWs & 1 & 76 & 1.28 & 97.44 \\
\hline Improper handling of sharp container by HCWs & 1 & 77 & 1.28 & 98.72 \\
\hline Lack of patient counseling & 1 & 78 & 1.28 & 100.00 \\
\hline
\end{tabular}

Table 4: Reasons and situations for needle stick injury (for the precorrective action phase)

\begin{tabular}{|c|c|}
\hline Reasons & Situations faced \\
\hline Improper segregation by trained HCWs & $\begin{array}{l}\text { Needle was discarded in black bin/red Bin/medicine trolley/dressing trolley/anesthesia trolley/ } \\
\text { pantry/female changing room/OT linen/paper/instrument tray/sink in the ambulance rather } \\
\text { than in sharp container }\end{array}$ \\
\hline Unavoidable accidents & $\begin{array}{l}\text { During IV cannulation, while giving insulin, while performing procedure/surgery, during } \\
\text { lumbar puncture, while assisting resuturing, during ear piercing, while washing instruments, } \\
\text { while withdrawing sample, while cleaning microtome knife, while handling used insulin } \\
\text { syringe, while suturing, while opening surgery blade, while handling used insulin syringe, } \\
\text { during grossing of liver, while checking RBS, and on doing root cause analysis, there was not } \\
\text { any breach observed in PPE usage, sharp/sharp container handling, and waste segregation }\end{array}$ \\
\hline Improper handling of sharps & $\begin{array}{l}\text { While performing cannulation/surgery, either the sharp was not kept in the kidney tray before } \\
\text { discarding it or the sharp was handed over to the other person without using the kidney tray }\end{array}$ \\
\hline Untrained HCWs & $\begin{array}{l}\text { Untrained HCWs handling sharp without the proper use of PPE, untrained HCWs handling } \\
\text { sharps and sample, and untrained person handling cleaning of biopsy gun }\end{array}$ \\
\hline Safety device not used for sample collection & While withdrawing sample of the patient \\
\hline Recapping & $\begin{array}{l}\text { Accidental prick while recapping the needle after checking RBS, after performing ascitic } \\
\text { tapping, and while recapping the lantus }\end{array}$ \\
\hline Improper handling of sharps container & While handling a sharps container that was filled up to top level \\
\hline Improper segregation by untrained HCWs & $\begin{array}{l}\text { Used needle was discarded on the floor and incident occurred while picking it up (without } \\
\text { using PPE) }\end{array}$ \\
\hline $\begin{array}{l}\text { Improper segregation and lack of patient } \\
\text { counseling }\end{array}$ & $\begin{array}{l}\text { Used insulin needle was discarded by patient's attendant in black bin and incident occurred } \\
\text { while picking it up }\end{array}$ \\
\hline
\end{tabular}

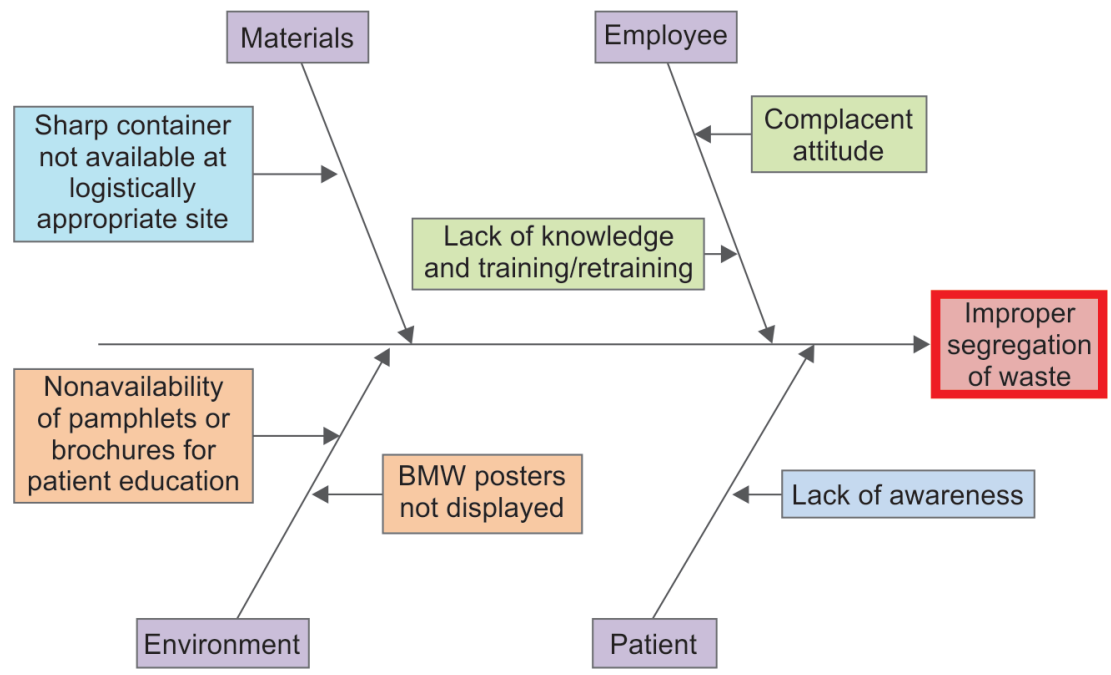

Fig. 3: Fishbone analysis of the most significant cause was carried out to determine the factors that could be responsible for needle stick injuries (for the precorrective action phase) 


\section{Discussion}

Needle site injury is a serious hazard, which exposes the HCWs to various dangerous drugs, microorganisms including multidrugresistant organisms, and biological materials. Many interventions have been recommended in an attempt to reduce the recognized risk and infection from NSIs. ${ }^{13}$

In our study, the NSI rate was 0.05 per HCW per year before intervention. Global burden of sharps injury in a study conducted by the WHO was estimated to be $0.2-4.7$ per HCW per year. ${ }^{14}$

A study conducted in Egypt shows a rate of $4.9 \mathrm{NSI}$ per HCW per year. ${ }^{15} \mathrm{~A}$ study conducted in a tertiary care hospital in Delhi shows the average number of NSIs ever for a HCW as $3.85 .{ }^{16}$ The NSI rate in our study is lower than the WHO estimates and the study done in Egypt.

The NSI rate per in-patient days could not be compared with study done by Sharma et al. in Delhi as the rates had been calculated differently. ${ }^{16}$

In the study by Gita et al., nursing had the highest rate of NSI at $54.5 \% .{ }^{17}$ Gholami et al. identified nurses to be at highest risk of NSIs among HCWs at $39.7 \% .{ }^{18}$ Similarly, in our study the rate of NSI was highest among the nurses at $26 \%$ followed by the housekeeping staff at $24 \%$.

The most common reason for NSI was improper segregation by trained HCWs (38.46\%) followed by unavoidable accidents (30.77\%), improper handling of sharps (11.54\%), improper segregation by untrained HCWs $(6.41 \%)$, recapping $(5.13 \%)$, safety device needle not used for blood sample collection (3.85\%), improper segregation by untrained HCWs, improper handling of the sharp container, and improper segregation with lack of patient counseling $(1.28 \%$ each). Similar to our study, NSI during handling and disposal of the biomedical waste was the most common situation for NSI for HCWs in the study conducted by Gita et al. (36.4\%). ${ }^{17}$ Segregation or the act of separating different types of waste is an imperative component of handling biomedical waste and should be done at the source of generation for all patient care areas including diagnostic services areas and procedure rooms.

In our study, reduction in the NSI rate was achieved through a comprehensive approach including adequate training of HCWs on handling and disposal of sharps, use of safety device, focusing on a safe environment like availability of a sharp container near the site of waste generation, and adequate display of BMW posters. There was a reduction in the NSI rate from 1.19 per 1,000 patient days to 0.63 per 1,000 patient days and from $0.05 \mathrm{NSI}$ per HCW to $0.03 \mathrm{NSI}$ per HCW per year. Similarly, a CDC report states that use of safetyengineered devices would reduce NSIs by $76 \% .{ }^{19}$

Multiple strategies help in reducing the burden of NSIs. Efforts toward providing structured training programs on safe use, handling, and disposal of sharps, changing the attitude and practice of HCWs, reinforcing use of devices with better safety features, and substitution of needles with safety devices help reduce NSIs. Baburao et al. in their study also recommended similar multipronged strategies. ${ }^{20}$

\section{Conclusion}

Needle site injury is a problem faced by all healthcare organizations. The main reasons accounting for NSIs were improper segregation, unavoidable accidents, and improper handling of sharps. Multiple approaches for all HCWs will help reduce the cases of NSI and probably also help in increasing the awareness to report cases.

\section{References}

1. Centre for Disease Control and Prevention (CDC) (2017) Healthcare Workers. The National Institute for Occupational Safety and Health (NIOSH).

2. Centers for Disease Control and Prevention (CDC) (2013). Stop Sticks Campaign. The National Institute for Occupational Safety and Health (NIOSH).

3. Healthcare wide hazards: needle stick/sharps injuries. Occupational Safety \& Health Administration. (https://www.osha.gov/SLTC/etools/ hospital/hazards/sharps/sharps.html. Accessed March 9, 2016).

4. Alonso A. Cementing sharps safety in the European Union: The importance of complying with the $2010 \mathrm{EU}$ council directive on sharps injury prevention. J Nurs Care 2014;3(03):1-2. DOI: 10.4172/21671168.1000169 .

5. Needlestick Safety and Prevention Act of 2000. PL 106.430. (http:// www.gpo.gov/fdsys/pkg/PLAW-106publ430/html/PLAW-106publ 430.html. Accessed December 4, 2015).

6. Centers for Disease Control and Prevention: Stop stick campaignNIOSH. (http://www.cdc.gov/niosh/stopsticks/sharpsinjuries.html. Accessed on 27th March 2015).

7. Rodrigues $C$. Needle stick injuries \& the health care worker - the time to act is now. Indian J Med Res 2010;131:384-386.

8. Jayanth ST, Kirupakaran H, Brahmadatan KN, et al. Needle stick injuries in a tertiary care hospital. Indian J Med Microbiol 2009;27(1): 44-47.

9. Azadi A, Anoosheh M, Delpisheh A. Frequency and barriers of underreported needlestick injuries amongst Iranian nurses, a questionnaire survey. J Clin Nursing 2011;20(3-4):488-493. DOI: 10.1111/j.1365-2702.2010.03252.x.

10. Jahangiri M, Rostamabadi A, Hoboubi N, et al. Needle stick injuries and their related safety measures among nurses in a university hospital, Shiraz, Iran. Saf Health Work 2016;7(1):72-77. DOI: 10.1016/j. shaw.2015.07.006.

11. Oh HS, Yoon Chang SW, Choi JS, et al. Costs of post exposure management of occupational sharps injuries in health care workers in the Republic of Korea. Am J Infect Control 2013;41(1):61-65. DOI: 10.1016/j.ajic.2012.01.030.

12. Yang L, Mullan B. Reducing needle stick injuries in healthcare occupations: an integrative review of the literature. ISRN Nurs 2011. DOI: 10.5402/2011/315432, Article ID 315432.

13. Rice BD, Tomkins SE, Ncube FM. Sharp truth: health care workers remain at risk of blood borne infection. Occup Med (Lond) 2015;65(3):210-214. DOI: 10.1093/occmed/kqu206.

14. Sharps injuries: Global burden of disease from sharps injuries to health-care workers. Geneva: World Health Organization; 2003. (WHO Environmental Burden of Disease Series, No. 3).

15. Talaat M, Kandeel A, El-Shoubary W, et al. Occupational exposure to needlestick injuries and hepatitis $B$ vaccination coverage among health care workers in Egypt. Am J Infect Control 2003;31(8):469-474. DOI: 10.1016/j.ajic.2003.03.003.

16. Study of Prevalence and Response to Needle Stick Injuries among Health Care Workers in a Tertiary Care Hospital in Delhi, India. (Rahul Sharma, SK Rasania, Anita Verma and Saudan Singh).

17. Gita N, Rao NP. Needle stick injuries in a tertiary care hospital in India: observations from a clinical audit. Int J Res Med Sci 2017;5(7): 2938-2942. DOI: 10.18203/2320-6012.ijrms20172593.

18. Gholami A, Borji A, Lotfabadi P, et al. Risk Factors of needlestick and sharps injuries among healthcare workers. Int J Hospital Res 2013;2(1):31-38.

19. Lal $P$, Singh MM, Malhotra $R$, et al. Perception of risk and potential occupational exposure to HIV/AIDS among medical interns in Delhi. J Commun Dis 2007;39(2):95-99.

20. Baburao B, Syam Sundar J. Study of prevalence and response to needle stick injuries among healthcare workers in a tertiary care hospital in Hyderabad, India. 